Chirurgia (2021) 116: 669-677

No. 6, November - December

Copyright@ Celsius

http://dx.doi.org/10.21614/chirurgia.116.6.669

\title{
Diagnostic and Therapeutic Particularities in Abdominal Trauma Associated with Spinal Cord Injuries - Review of the Literature
}

\author{
Valentin Titus Grigorean ${ }^{1,2}$, Ionuț Simion Coman ${ }^{1,2^{*}}$ \\ 'Department of General Surgery, "Bagdasar-Arseni" Clinical Emergency Hospital, Bucharest, Romania \\ 2"Carol Davila" University of Medicine and Pharmacy, Bucharest, Romania
}

*Corresponding author: Ionuț Simion Coman, MD General Surgery Department „Bagdasar-Arseni” Clinical Emergency Hospital Berceni Street, No. 12, $4^{\text {th }}$ District Bucharest, Romania

E-mail: ionut.coman@umfcd.ro

\section{Rezumat}

Particularități diagnostice și terapeutice în trauma abdominală asociată traumatismelor vertebromedulare - review al literaturii

Asocierile morbide posttraumatice pot evolua de sine stătător sau pot interrelaționa, realizând efecte de însumare sau potențare a gravității. Uneori efectele cumulative sau potențatoare se asociază cu manifestări derutante de ordin clinic şi paraclinic, induse de una din entitățile componente ale complexului lezional sau prin efecte reciproc agravante. Este şi cazul traumatismelor vertebromedulare asociate altor leziuni posttraumatice, unde semnalul neurologic viciat poate induce particularități de manifestare a leziunilor asociate. Şocul spinal posttraumatic, disreflexia autonomă şi sechelele de ordin motor, senzorial şi autonom aduc distorsionări ale semnalului neurogen, ce vor influența semnificativ alte teritorii traumatizate, generând manifestări clinice şi elemente reacționale atipice. Prototipul acestei asocieri morbide posttraumatice este reprezentat de complexul lezional traumatism vertebromedular traumatism abdominal.

Cuvinte cheie: traumatism vertebromedular, şoc spinal, disreflexie autonomă, traumatism abdominal

\section{Abstract}

Post-traumatic morbid associations may evolve by themselves, or can interact, with effects of adding or potentiating gravity. 
Sometimes cumulative or potentiating effects are associated with clinical and paraclinical confusing manifestations induced by one of the components of the lesion complex, or by mutually aggravating effects. It is also the case of vertebromedular traumas associated with other post-traumatic lesions, where the neurological signal is distorted, and may induce particularities of associated lesions. Posttraumatic spinal shock, autonomic dysreflexia and motor, sensory and autonomous after effects, bring distortions of the neurogenic signal, which will significantly affect other traumatized territories, generating clinical manifestations and atypical reaction elements. The prototype of this post-traumatic morbid association is represented by the lesion complex vertebromedular trauma abdominal trauma.

Key words: vertebromedular trauma, spinal shock, autonomic dysreflexia, abdominal trauma

\section{Introduction}

Craniocerebral, thoracic, abdominal and osteoarticular traumas are frequently produced in polytrauma cases, which are associated with vertebromedular trauma. Although the $\mathrm{Co}^{-}$ existence of vertebromedular trauma with abdominal trauma is not the most common association, the diagnostic and therapeutic particularities of abdominal trauma of the patient with post-traumatic spinal cord injuries are most common and wide, generating mutually aggravating consequences. If abdominal trauma can affect spinal cord injury by haemorrhagic/traumatic shock, severe anaemia, sepsis, etc., vertebromedular trauma negatively affects the abdominal state through spinal shock, autonomic dysreflexia, sensitivity disorders and movements in the sublesional segment (including the abdominal wall), spasticity or visceral paresis with significant diagnostical, therapeutic and evolutionary consequences.

\section{Discussions}

The analysis of the diagnostic, therapeutic and evolutionary particularities of abdominal traumas coexisting with vertebromedular traumas should take into account the lesional polymorphism of post-traumatic spinal cord damage. Thus, the severity of the medullary injury, the topography and the evolutionary phase are the main coordinates of the spinal cord injury.
The severity assessment of vertebromedular trauma is clinically performed by establishing the Frankel and ASIA scale impairment [Tables 1, 2, after $(1,2)$ ].

The topography of the medullary injury is essential for the occurrence of disturbances in the subinjury segments. Thoracic fractures (T5-T12) may have direct consequences on abdominal sensitivity and motility, and the proximal lesions caused by $\mathrm{T} 5$ affect the condition of the viscera and abdominal wall by disconnecting the upper/lower segments, with reduced or abolished distal activity (Figs. 1-3).

Evolutionary phases of spinal cord injury, through the specific changes of the period after the trauma, may affect visceral peristaltics, sensitivity and motor function of the abdominal wall, sphincter function, etc (3).

Spinal shock is installed immediately posttraumatic and it can lasts 3 to 80 days (4). The occurrence of infectious complications may extend this period. Spinal shock progresses in four phases, from atony/areflexia to late hyperreflexia. It may induce diagnostic error factors by eliminating spinal functions caudal from the

Table 1. Frankel scale

\begin{tabular}{lll}
\hline \multicolumn{2}{l}{ Grade } & Description \\
\hline A & Complete & No motor or sensory function below level of lesion \\
\hline B & Sensory only & $\begin{array}{l}\text { No motor function, but some sensation preserved } \\
\text { below level of lesion }\end{array}$ \\
\hline C & Motor useless & Some motor function without practical application \\
\hline D & Motor useful & Useful motor function below level of lesion \\
\hline E & Recovery & $\begin{array}{l}\text { Normal motor and sensory function, may have } \\
\text { reflex abnormalities }\end{array}$ \\
\hline
\end{tabular}


Table 2. American Spinal Injury Impairment Scale

\begin{tabular}{lll}
\hline Grade & Description \\
\hline A & Complete & No motor or sensory function is preserved in the sacral segments S4-S5 \\
\hline B & Incomplete & $\begin{array}{l}\text { Sensory function preserved but not motor function is preserved below the neurological level and includes the sacral segments } \\
\text { S4-S5 }\end{array}$ \\
\hline C & Incomplete & $\begin{array}{l}\text { Motor function is preserved below the neurological level, and more than half of key muscles below the neurological level have a } \\
\text { muscle grade less than 3 }\end{array}$ \\
\hline D & Incomplete & $\begin{array}{l}\text { Motor function is preserved below the neurological level, and at least half of key muscles below the neurological level have a } \\
\text { muscle grade of 3 or more }\end{array}$ \\
\hline E & Normal & Motor and sensory function are normal \\
\hline
\end{tabular}

level of medullary injury or inadequate muscle response. These phenomena may lead to the modification, suppression or disappearance of abdominal symptoms in case of coexistence of significant abdominal trauma.

The factors which influence the sublesions segments are sensory deficiency, decreased/ loss of the somatic reflex activity, loss of striated muscle tone, detrusor and rectal muscle areflexia, arterial hypotension (in cervical spinal cord lesions), bradycardia, etc (5-8).

If the spinal shock is extended, the loss of the facilitator's supraspinal functions can be observed, hypersensitivity denervation as

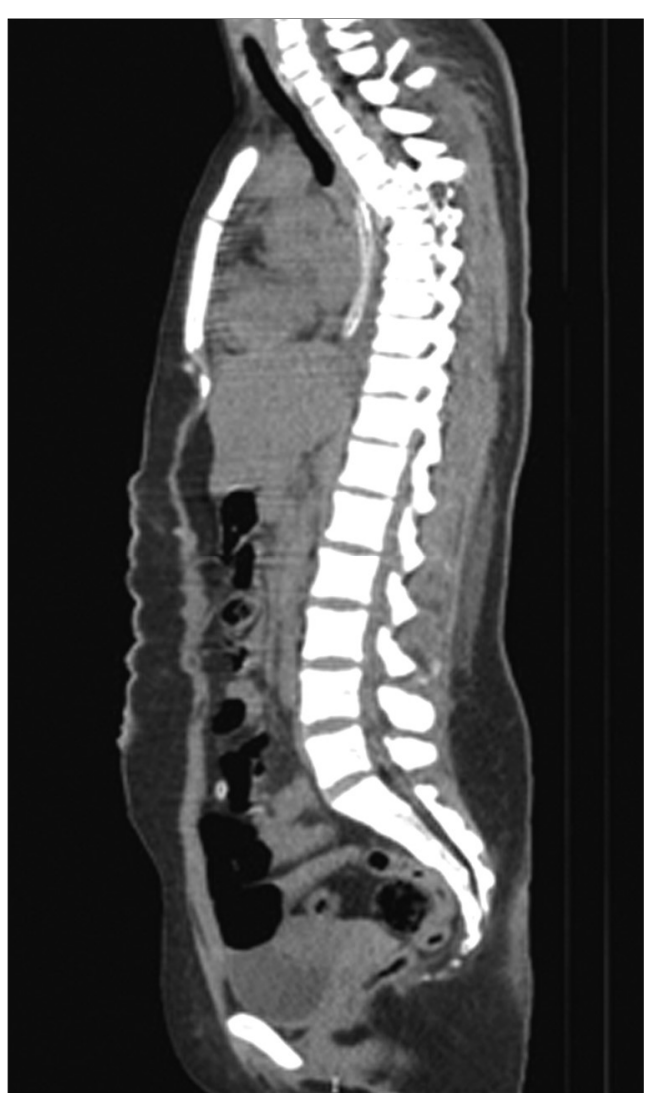

Figure 1. Sagital section of the spine of a 21-years-old female patient from a car crash, with severe spinal cord injury, anterolisthesis and laterolisthesis at T4-T5 level, Frankel A classification; vertebromedular trauma associated with abdominal trauma - hemoperitoneum by ruptured spleen

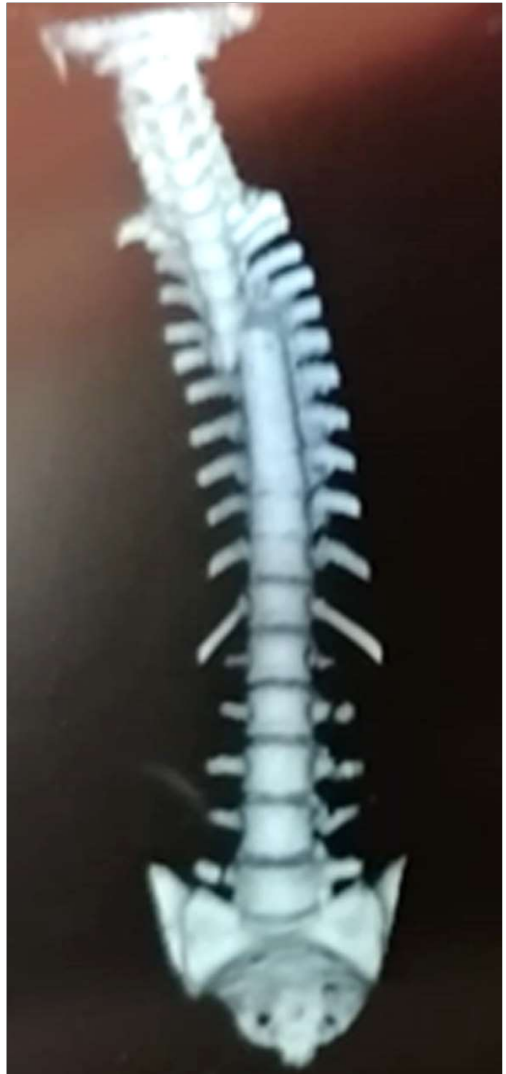

Figure 2. 3D reconstruction of the spine of a 21-years-old female patient from a car crash, with severe spinal cord injury, anterolisthesis and laterolisthesis at T4-T5 level, Frankel A classification; vertebromedular trauma associated with abdominal trauma - hemoperitoneum by ruptured spleen

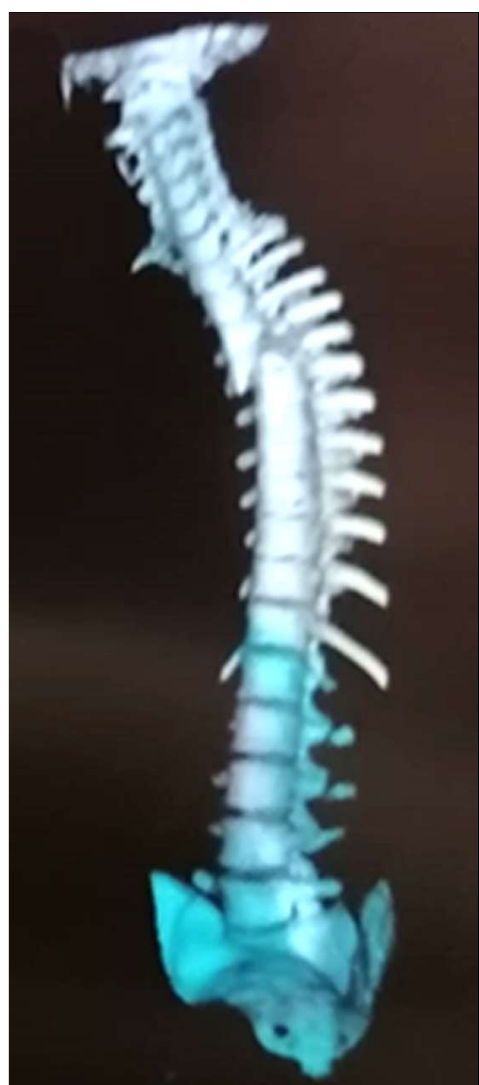

Figure 3. 3D reconstruction of the spine of a 21-years-old female patient from a car crash, with severe spinal cord injury, anterolisthesis and laterolisthesis at T4-T5 level, Frankel A classification; vertebromedular trauma associated with abdominal trauma hemoperitoneum by ruptured spleen 
well, and from a morpho-functional point of view, the occurrence of dependent axon/ somatic synaptic regeneration is noticed. These elements may cause difficulties in the assessment of the clinical status of the abdomen, the haemodynamic status of the patient and the occurrence of elements with septic connotation.

The coexistence of spinal shock with haemorrhagic/traumatic shock raises additional problems of diagnosis and typological identification, by the interference of clinicalparaclinical elements and the reaction changes (these as well permanently dynamic) with abdominal, pulmonary, renal or general resonance. The confirmed spinal shock does not exclude the coexistence of another type of shock. Haemorrhagic shock is difficult to recognise under the conditions of impairment of autonomic functions, which prevents the installation of definitive manifestations for haemorrhagic shock (tachycardia, peripheral vasoconstriction, etc.) (9-15).

These are the considerations for which to a patient with spinal shock, the coexistence of haemorrhagic shock should be taken into account until the evidence to the contrary is conclusive (16). Monitoring of haemodynamic, haematological, specific imaging (abdominal ultrasound or CT scan with intravenous contrast), diagnostic peritoneal lavage or laparoscopy may sometimes be necessary to exclude these severe posttraumatic entities. The completion of the spinal shock phase is announced by the installation of the bulbocavernous reflex, the reappearance of osteotendon reflexes and the reflex function of the detrusors.

Autonomous dysreflexia is a complex clinical consequence that may occur after the spinal shock remission. Cases of early autonomic dysreflexia, overlay by the spinal shock period have been reported. It consists of the appearance of a sympathetic paroxystic response to various stimuli acting below the injury level.

It is specific to high vertebral spinal cord lesions (above level T5-T6), cranial of the splanchnic sympathetic chain. The central clinical element is represented by malignant arterial hypertension, which makes it difficult to identify general signs of haematological loss and other pathological circumstances associated with a drastic decrease of volemia. Various stimuli, generally innocuous (deep visceral distension, bladder catheterisation, evacuation enemas, digital stimulation during the intestinal emptying procedure, menstruation, deep vein thrombosis, the contact with sharp objects, pain, etc.) may trigger a sympathetic violent reaction, with the installation of autonomous dysreflexia (17-19).

The sympathetic storm of a haemorrhagic event may hide the local and general clinical signs of a digestive haemorrhage or the occurrance of hemoperitoneum and make it difficult to interpret the haemorrhagic parameters pursued in dynamics. High secondary motor, sensory and autonomous vertebromedular trauma deficiencies have a drastic effect on the symptoms and the abdominal clinic $(20,21)$.

The lesions with topography T5-T12 may cause flaccid paralysis of the abdominal muscles with the abolition of abdominal skin reflexes. The sensitive component of upper topographic lesions may induce abdominal wall sensitivity disorders (hypoaesthesia, anaesthesia), which may be confusing to the abdominal clinical examination. The effect of autonomic nervous system damage is to change the characteristics of visceral pain, which is extremely poorly defined, vague and diffuse. When the medullary lesions are not complete, visceral pain may be perceived, but it is difficult to be located, it can rather be in more connection with the areas corresponding to the embryonic origin of the affected abdominal viscera and less with the topographic projection at the abdominal wall level $(22,23)$.

The referred pain is the pain perceived at a distance from the real stimulus and is a physiological consequence of the phenomenon of "visceral-somatic convergence". There are known the right hemithoracic pain in the gallbladder, shoulder pain in phrenic irritations, inguinoscrotal pain in the nephretic colic, etc. Following the production of severe vertebromedular trauma, reflex pain may have an 
atypical character, or may be absent (24-26).

Various vascular disorders (ischaemia, segmentation bruises, etc.) or trophic disorders with uncertain pathogens may occur at the abdominal wall level, making clinical interpretation difficult (27).

The supraaddition of a severe infectious factor (frequently encountered) regardless of its location, brings with it additional clinical, paraclinical and laboratory elements that make their interpretation and the hierarchy of therapeutic measures increasingly difficult.

Radiological investigations involving the maintenance of orthostatism may not be carried out and to perform them in lateral decubitus is indicated after surgical immobilisation of the vertebral spine fracture. Other imaging investigations may be performed according to standard protocols (ultrasound and CT scan with intravenous contrast).

In summary, we note that a number of clinical data defining an abdominal trauma with a surgical visa, or the occurrence of subsequent abdominal complications, may have an atypical or absent clinic. Flaccid paralysis with removal of the sensitivity of the abdominal wall muscle may hide the peritoneal irritation without mounting the defence or muscle contraction. The trending visceral distension with the decrease or abolition of peristaltics, produces trending ileus with the risk of diastatic perforation or difficulties in differential diagnostic with mecano-inflammatory occlusion. Sometimes paretic intestinal ileus can present mecano-inflammatory complications (intussusception, volvulus, etc.) (28).

The impressive volume of fluid and electrolytes seized in the enteroperitoneal and pleural space, generates severe dehydration phenomena, which are difficult to be therapeutically managed. Wide oscillations of blood presure (from vasoplegic with severe refractory low blood pressure to sympathetic storms with malignant high blood pressure) make it difficult to assess the actual haemodynamic status of the patient. Thermal disturbances may hide a septic syndrome in progress, or by hyperpyrexia may create a confusing clinical context.
Post-traumatic abdominal injuries which have been diagnosed in the emergency to the patients with associated vertebromedular trauma, are treated medically and surgically according to standard procedures (e.g. spleen rupture requires urgent splenectomy).

The most difficult problems are related to abdominal lesions with evolutionary potential, difficult to follow to a patient with severe vertebromedular trauma, or subsequent abdominal complications, which have an atypical development in the context of a major spinal cord injury. Gastrointestinal function is modified according to a number of factors such as the time elapsed from trauma, the level and severity of the medullary injury, local factors (previous abdominal surgery, peritoneal adhesions, pre-existing abdominal disease, etc.). In the acute phase of vertebromedular trauma spinal shock appears with the abolition of sublesions neurological functions, and in the chronic phase the neurogenic intestine, which behaves as an autonomous lesion, developing a series of complications with particular, atypical manifestations.

In addition, the digestive tract (along with the urinary and pulmonary tract) is a sensitive resonator in all severe pathological entities (burns, severe septic conditions, traumatic brain injury, etc.) including the severe vertebromedular trauma. Chemical mediators, the participation of the neurogenic component through extrinsic innervation (parasympathetic, sympathetic and somatic) and intrinsic, have an influence up to the level of the visceral smooth muscle plate and on enteral microcirculation with significant functional consequences.

The patient with spinal cord trauma may develop any type of abdominal surgical pathology like any other patient, noting that the probability of this pathological situation is higher, either as a result of abdominal lesions caused at the time of the accident, which may have an evolutionary character, or as a result of the degeneration in the entero-peritoneal space of secondary complex neurological disorders of vertebromedular trauma. With the exception of abdominal lesions induced by 
trauma, the main pathological entities encountered are acute abdomen, upper digestive haemorrhage and intestinal occlusion.

Acute surgical abdomen may be the consequence of pneumoperitoneum in the perforated gastric or duodenal ulcer, other visceral perforations, ruptured abscesses in the peritoneal cavity, acute inflammatory processes of the organ (cholecystitis, pancreatitis, appendicitis) or entero-mesenteric infarction (29). The perforated ulcer appears in the conditions of a pre-existing injury, exacerbated in the traumatic context or as a result of acute digestive stress injury, aggressive drugs on the gastric mucosa (cortisone) and interruption of necessity for oral nutrition (swallowing disorders, prolonged nasal-gastric aspiration, etc.). The perforation of cavitar viscera may appear under conditions of abdominal distension with the absence of peristalsis and profound changes in visceral microcirculation. The same mechanisms also seems to be involved in the inflammatory processes of the organ (acute alithiasic cholecystitis).

The most common manifestations of acute abdominal pain of these patients are: triggering of successive episodes of autonomic dysreflexia, tachypnea, diffuse abdominal pain, abdominal distension, discharge vomiting, urinary bladder spasm, increased spasticity of the lower limbs, changes in blood pressure. Fever may be absent. A sign with high diagnostic value is the increase of the ventricular rate (30-33).

After resumption of reflex activity, in the upper cervical and thoracic lesions, spastic paralysis of the striated muscle with contracted abdomen occurs in the absence of acute abdomen.

The evaluation of the spasticity of the entire striated muscle into sublesional spinal cord may help to avoid a false positive diagnosis of acute abdomen (although isolated spasticity at pelvic limbs level may be suggestive for this diagnosis).

Upper digestive haemorrhage is the most common complication of vertebromedular trauma during acute periods through bleeding ulcerative lesions and seldomly by perforating lesions.

Locating at the upper gastric pole is the most common and it is characterized by multiple superficial lesions with the size which is not directly proportional to the flow of bleeding. Sometimes digestive bleeding occurs in the presence of pre-existing lesions of the upper digestive tract. The pathogenic factors frequently involved in the initiation of these lesions are: topography and severity of vertebromedular trauma, prolonged and severe low blood pressure, microthromboses at the wall of the cavity organs, septicity, repeated blood transfusions, duodenogastric reflux, oral suppression, aggressive drugs on the gastric and duodenal mucosa, oral suppression, long-term mechanical ventilation, etc (34-36)

The assessment of the severity of the haemorrhage is done according to the Orfanidi criteria and the measures taken are identical to those applied to non-traumatic patients, but taking into account the haemodynamic particularities of the traumatised vertebromedullary patient $(37,38)$.

Bowel obstruction is a quasi-permanent complication of patients with severe spinal cord injury. Usually these patients develop a "neuro muscular occlusion" falling into the category of dynamic ileus, which may be remitted under consistent conservative treatment, or may develop into peritonic or mechano-inflammatory complications. The most frequent dynamic ileus is seen at patients with ASIAA and B spinal cord injury, whereas in ASIA E cases, this complication is practically non-existent.

Debuted as a primary intestinal peristaltic disorder, dynamic occlusion trains the mechanisms of pseudo-global obstruction or secondary mechano-inflammatory occlusions with severe local and systemic consequences. The delimitation of these entities is done by corroborating clinical, biological, imaging and evolutionary data. It is not uncommon for the data collected to be full of ambiguity, creating difficulties on the appropriate framework of measures which are required. 
The refractory nature of functional bowel obstructions creates diagnostic doubts and may generate unnecessary laparotomies, which aggravates the patient's condition.

Diagnostic imaging in such cases is represented by ultrasound and abdominal tomography, conventional radiology cannot be used due to the impossibility of maintaining orthostatism. The lateral decubitus is limited to the patient with the non-mobilised spine. The use of barite contrast is contraindicated and endoscopic investigations are allowed.

Iodine substances may be used for oral administration, but with questionable results (digestive paresis), clyster of any type are contraindicated. Intravenous contrast may be used (39).

Sensitive diagnostic problems and therapeutic attitude arise in situations where posttraumatic dynamic ileus is also associated with other intraperitoneal lesions (40). If these injuries precipitate an emergency surgery, it may also be useful to adopt a surgical gesture for digestive paresis (low external derivation).

In summary, it is noted that:

- Neurogen shock is present in severe posttraumatic vertebral damage upper than T6 level.

- Sensitive, motor and autonomic disorders alter the clinical manifestations both in the spinal and subacute/ chronic phases, overlaping as well during autonomic dysreflexia.

- The real haemodynamic status of the patient is difficult to evaluate.

- The secondary digestive paresis in spinal cord trauma should be closely monitored and evaluated to identify a possible complication requiring surgery.

- The septic component (frequently involved) widens confusingly clinical manifestations and raises case management problems.

- In view of the particularities of these patients, the multitude of factors with implications in the abdominal sphere and the mutually aggravating mechanisms, digestive/abdominal complications are very common and should be anticipated or treated as soon as possible.

\section{Therapeutic Particularities}

The prophylaxia of abdominal complications refers to a set of measures aimed to prevent, reduce or delay the occurrence of digestive disorders, avoiding a surgical procedure that would be an additional aggression against an extremely fragile patient.

Resources used are: dietary hygiene measures, avoidance of high blood pressure, gastric and prokinetic protection medication, permanent urinary bladder catheterisation, effective nasogastric aspiration during manifest ileus periods, progressive resumption of oral nutrition as soon as possible, prophylaxis of infections, measures to stimulate peristaltics and manual emptying of the rectal ampulla, avoidance of triggering factors of autonomous dysreflexia episodes, etc.

The general treatment of complications is coordinated according to two principles: the early diagnosis and the use of least traumatic methods (medical treatments, medical procedures that can improve the situation, endoscopic or interventional radiology methods, etc). Throughout the entire development period, physiological parameters of the body (blood pressure, ventricular passage, diuresis, haematological, renal, hepatic, ionogram, plasma proteins, coagulation, etc) should be kept as close as possible to normal.

In case of confirmation of an injury with a clear surgical indication, the intervention should be as prompt and less traumatic as possible. In the event of laparoscopy or laparotomy, pre-emptive surgical procedures (drainage of areas where biological fluids can be retained, external derivations at the lower digestive tract level, etc) may also be performed after the repair of the princeps lesion. In the absence of diagnostic elements of certainty, "abdominal alert" signs will be followed dynamically, such as high blood pressure fluctuations, unjustified clamping of diuresis, precipitation of autonomic dysreflexia and lack of response to treatment, tachypnea and tachycardia, increase in the amount of digestive aspirate, isolated spasticity in the lower limbs, etc. 
All these elements predict or announce the occurrence of an abdominal complication (24). Their correlation with paraclinical and laboratory data for each individual case may reduce the risk of a diagnostic error (41).

Surgical interventions for patients with severe vertebrae damage will be performed under general anaesthesia with orotracheal intubation. Although it has its own posttraumatic anaesthesia, general anaesthesia is necessary to prevent the installation of autonomic dysreflexia episodes during surgical procedures. Spinal anesthesia is contraindicated. Reduced-scale interventions may be performed with local intravenously potentiated anaesthesia.

Postoperatively development of the traumatised vertebromedular patient is affected by a significantly higher number of local and general complications. Difficulties in the resumption of intestinal transit, residual abscesses, anastomotic fistulae, evisceration, secondary atone lesions of parietal suppuration, etc. Generally there are frequent cases of bronchopneumonia, pleural effusion, pulmonary and coronary thromboembolic accidents.

\section{Conclusions}

1. Patients with vertebromedular trauma are a special category of patients requiring a particular diagnostic and therapeutic approach.

2. Most of vertebromedular trauma's interferences are with the abdominal sphere, through concomitant lesions, but mostly through multiple mutually aggravating physiopathological chains.

3 . The damage of digestive tract is present from the spinal shock phase to the subacute and chronic phases, mainly in the lesions above T5-T6 levels.

4. The digestive changes have certain characteristics of manifestation depending on the evolutionary stage of vertebromedular trauma without having an absolute specificity.

5. Spinal shock may be accompanied by haemorrhagic or traumatic shock and dominant clinical manifestations may lead to diagnostic errors or omissions.

6. Wide blood pressure oscillations, by interfering with adaptive mechanisms which are neurologically impaired (vasoplegia, autonomic dysreflexia, etc), sometimes make it difficult to assess the real haemodynamic status of the patient.

7. Persistent low blood pressure, refractory during the treatment requires a thorough search for a haemorrhagic source. Low blood pressure can be attributed to neurogenic shock, only in the case when the haemorrhage is certain denied.

8. Neurological manifestations, including digestive manifestations (sensory disturbances, motor, autonomous, etc.) accompanies all stages of post-traumatic development in a sequence or association sometimes unexpected or hard to explain, which makes clinical assessment of abdominal condition difficult.

9. The patient's abdominal status should be evaluated taking into account the specificities of severe spinal cord disease.

10. Given the high frequency of digestive complications to these patients, the early establishment of prophylactic measures is justified, and early diagnosis confirmation is vital.

\section{Conflict of Interests}

The authors declare no conflict of interests.

\section{References}

1. Frankel HL, Hancock DO, Hyslop G, Melzak J, Michaelis LS, Ungar GH, et al. The value of postural reduction in the initial management of closed injuries of the spine with paraplegia and tetraplegia. Paraplegia 1969; 7:179-92.

2. Roberts TT, Leonard GR, Cepela DJ. Classifications In Brief: American Spinal Injury Association (ASIA) Impairment Scale. Clinical Orthopaedics and Related Research 2017:475:1499.

3. Topographic and Functional Anatomy of the Spinal Cord: Gross Anatomy, Ventral and Dorsal Roots, Descending Spinal Cord Tracts n.d. https://emedicine.medscape.com/article/1148570-overview (accessed November 24, 2021).

4. Ditunno JF, Little JW, Tessler A, Burns AS. Spinal shock revisited: a four-phase model. Spinal Cord. 2004;42(7):383-95.

5. White RJ, Likavec MJ. Spinal shock--spinal man. J Trauma. 1999;46(5): 979-80.

6. Ko H-Y. Revisit Spinal Shock: Pattern of Reflex Evolution during Spinal 
Shock. Korean J Neurotrauma. 2018;14(2):47-54.

7. Silver JR. Spinal shock revisited: a four-phase model (1). Spinal Cord. 2005;43(7):450

8. Atkinson PP, Atkinson JL. Spinal shock. Mayo Clin Proc. 1996;71(4):384-9.

9. Levi L, Wolf A, Belzberg H. Hemodynamic parameters in patients with acute cervical cord trauma: description, intervention, and prediction of outcome. Neurosurgery. 1993;33(6):1007-16; discussion 1016-7.

10. Saadeh YS, Smith BW, Joseph JR, Jaffer SY, Buckingham MJ, Oppenlander ME, et al. The impact of blood pressure management after spinal cord injury: a systematic review of the literature. Neurosurg Focus. 2017;43(5):E20.

11. Hawryluk G, Whetstone W, Saigal R, Ferguson A, Talbott J, Bresnahan J, et al. Mean Arterial Blood Pressure Correlates with Neurological Recovery after Human Spinal Cord Injury: Analysis of High Frequency Physiologic Data. J Neurotrauma. 2015;32(24):1958-67.

12. Lee YS, Kim KT, Kwon BK. Hemodynamic Management of Acute Spinal Cord Injury: A Literature Review. Neurospine. 2021;18(1):7-14.

13. Tee JW, Altaf F, Belanger L, Ailon T, Street J, Paquette S, et al. Mean Arterial Blood Pressure Management of Acute Traumatic Spinal Cord Injured Patients during the Pre-Hospital and Early Admission Period. J Neurotrauma. 2017;34(6):1271-1277.

14. Kong CY, Hosseini AM, Belanger LM, Ronco JJ, Paquette SJ, Boyd MC, et al. A prospective evaluation of hemodynamic management in acute spinal cord injury patients. Spinal Cord. 2013;51(6):466-71.

15. Dakson A, Brandman D, Thibault-Halman G, Christie SD. Optimization of the mean arterial pressure and timing of surgical decompression in traumatic spinal cord injury: a retrospective study. Spinal Cord. 2017; 55(11):1033-1038.

16. Chin LS, Mesfin FB, Dawodu ST. Spinal Cord Injuries Clinical Presentation. Medscape 2018.

17. Spinal Cord Injury: Autonomic Dysreflexia I HealthLink BC n.d. https:// www.healthlinkbc.ca/health-topics/ug2980 (accessed November 24, 2021).

18. Novak P. Autonomic Disorders. Am J Med. 2019;132(4):420-436.

19. Allen KJ, Leslie SW. Autonomic Dysreflexia. The Curated Reference Collection in Neuroscience and Biobehavioral Psychology 2021:345-7.

20. Morgan S. Recognition and management of autonomic dysreflexia in patients with a spinal cord injury. Emergency Nurse: The Journal of the RCN Accident and Emergency Nursing Association 2020;28:22-7.

21. Cowan $\mathrm{H}$, Lakra C, Desai M. Autonomic dysreflexia in spinal cord injury. BMJ. 2020;371:m3596.

22. Wan D, Krassioukov AV. Life-threatening outcomes associated with autonomic dysreflexia: A clinical review. J Spinal Cord Med. 2014;37(1):2-10

23. Flack CK, Mellon MJ. Current management strategies for autonomic dysreflexia. Curr Bladder Dysfunct Rep 2018;13:224-9.

24. Soler MD, Kumru H, Vidal J, Pelayo R, Tormos JM, Fregni F, et al. Referred sensations and neuropathic pain following spinal cord injury. Pain 2010; 150:192-8.

25. Siddall PJ, McClelland JM, Rutkowski SB, Cousins MJ. A longitudinal study of the prevalence and characteristics of pain in the first 5 years following spinal cord injury. Pain 2003;103:249-57.

26. Hulsebosch CE, Hains BC, Crown ED, Carlton SM. Mechanisms of chronic central neuropathic pain after spinal cord injury. Brain Research Reviews 2009;60:202-13

27. Han ZA, Choi JY, Ko YJ. Dermatological problems following spinal cord injury in Korean patients. The Journal of Spinal Cord Medicine 2015;38:63.

28. Medical Complications in Spinal Cord Injury - Physiopedia n.d. https://www.physio-pedia.com/Medical_Complications_in_Spinal_ Cord_Injury (accessed November 24, 2021).

29. Juler GL. Acute Abdominal Emergencies in Spinal Cord Injury Patients. The Journal of The American Paraplegia Society 1979;2:1-5.

30. Eltorai I, Schmitt J. Emergencies in chronic spinal cord injury patients. Demos Medical Publishing LLC; 2002

31. Levi R, Hultling C, Nash MS, Seiger A. The Stockholm spinal cord injury study: 1. Medical problems in a regional SCI population. Paraplegia 1995; 33:308-15.

32. Nepomuceno C, Fine PR, Richards JS, Gowens H, Stover SL, Rantanuabol $\mathrm{U}$, et al. Pain in patients with spinal cord injury. Archives of Physical Medicine and Rehabilitation 1979;60:605-9.

33. Yezierski RP. Pain following spinal cord injury: pathophysiology and central mechanisms. Progress in Brain Research 2000;129:429-49.

34. el Masri W, Cochrane P, Silver JR. Gastrointestinal bleeding in patients with acute spinal injuries. Injury 1982;14:162-7.

35. Albert TJ, Levine MJ, Balderston RA, Cotler JM. Gastrointestinal complications in spinal cord injury. Spine 1991;16:S522-5.

36. Gore RM, Mintzer RA, Calenoff L. Gastrointestinal complications of spinal cord injury. Spine 1981;6:538-44.

37. Anwar F, Khayer A, El-Mahrouki H, Purcell M. Gastrointestinal bleeding in spinal injuries. Is prophylaxis essential? Bristish Journal of Medical Practitioners 2013;6:a607.

38. CA Soderstrom TD. Increased susceptibility of patients with cervical cord lesions to peptic gastrointestinal complications. J Trauma 1985;25:1030-8.

39. Nino-Murcia M, Friedland GW. Functional abnormalities of the gastrointestinal tract in patients with spinal cord injuries: evaluation with imaging procedures. AJR American Journal of Roentgenology 1992;158:279-81.

40. Miller F, Fenzl TC. Prolonged ileus with acute spinal cord injury responding to Metoclopramid. Paraplegia 1981;19:43-5.

41. Sarrfakıoglu B, Afșar SI, Yalbuzdag ȘA, Ustaömer K, Ș Ayaș. Acute abdominal emergencies and spinal cord injury; our experiences: a retrospective clinical study. Spinal Cord. 2014;52(9):697-700. 